\title{
Forensic toxicology: biological sampling and use of different analytical techniques
}

\begin{abstract}
Forensic toxicology deals with the investigation of drugs of abuse or toxic substances. This field involves toxicology and other disciplines such as biotechnology, pharmacology, analytical- and clinical chemistry to aid the legal investigation to find out the actual cause of death. Forensic toxicology incorporates a number of analytical techniques for detection of drugs from a variety of samples procured from the subjects. Various techniques used for different samples types are enlisted in the paper. The present paper reviews the different biological samples taken and techniques used for such investigations. The paper also highlights the importance and role of forensic toxicology as a branch of high precision involving different state of art techniques including PCR and DNA profiling for finding various hitches in a number of criminal and accidental cases.
\end{abstract}

Volume 4 Issue 4 - 2017

\section{Zorawar Singh}

Department of Zoology, Khalsa College, India

Correspondence: Zorwar Singh, Department of Zoology, Khalsa College, Amritsar, Punjab, I4300I, India,

Tel91-94I7230075, Email zorawarsinghs@rediffmail.com

Received: March 03, 2017 | Published: April 17, 2017

Keywords: forensic, toxicology, hair, blood, urine, analytical techniques, DNA

\section{Introduction}

Forensic science is the branch of science dealing with the analysis of collected evidences during investigation of a crime scene. The branch emphasizes the manner of death and tries to find out the actual cause of death. Forensic toxicology is a modern scientific field which involves the use of different analytical techniques like laser diode thermal desorption-tandem mass spectrometry (LDTD-MS-MS), ${ }^{1}$ Hyphenated liquid chromatographic techniques, ${ }^{2}$ Chromatography by silica-gel chromatobars, ${ }^{3}$ Ultra-high performance liquid chromatography-tandem mass spectrometry, ${ }^{4}$ DNA typing, ${ }^{5}$ and capillary electrophoresis. ${ }^{6}$ Forensic findings through these techniques may include the determination of pesticides, drugs, natural products, industrial chemicals, metals and pollutants. A toxicological analysis can be done to various kinds of samples procured from subjects under investigation. Blood, urine, nails, hair, bile, gastric contents, liver and brain tissue can all be useful specimens. There is a gradual increase in the demand of modern analytical techniques involved in forensic toxicology in solving disputes. Figure 1 shows the number of papers published on forensic toxicology from 2007 to 2016 (Ten years). The number of papers in each year was searched using PubMed database. The lowest number of papers was found in $2008(\mathrm{~N}=4)$ and maximum was in $2010(\mathrm{~N}=18)$. The trendline shows a regular increase in the number of papers showing the popularity and importance of the field of forensic toxicology. The ever increasing popularity of the field of forensic toxicology in solving the criminal, suicidal and accidental cases has shown the importance of this particular field. The present paper reviews the different techniques used for the determination of a number of drugs from a variety of biological samples used for the forensic toxicological analysis.

\section{Hair}

Hair has been used extensively for forensic toxicological assessments. Hair has been used for years in the assessment and documentation of human exposure to drugs. ${ }^{7}$ Sample collection is performed in a noninvasive manner. Hair analysis for abused drugs has been gaining increasing significance in forensic sciences. ${ }^{8}$ For these reasons, testing for drugs in hair provides unique and useful information in several fields of toxicology, from which the most prominent is the possibility of studying individual drug use histories by means of segmental analysis. ${ }^{7}$ Hair is a special matrix for the retrospective investigation of chronic drug abuse or poisoning in criminal cases and allows to demonstrate with sensitive methods even a single administration in low amount. ${ }^{8}$ Various reports emphasize the use of hair in finding out the causes of death. ${ }^{7-10}$ Ethyl glucuronide $(\mathrm{EtG})$ is a minor and direct metabolite of ethanol. EtG is incorporated into the growing hair allowing retrospective investigation of chronic alcohol abuse. Kharbouche et al.,9 reported the development and the validation of a method using gas chromatography-negative chemical ionization tandem mass spectrometry (GC-NCI-MS/MS) for the quantification of $\mathrm{EtG}$ in hair. ${ }^{9} \mathrm{EtG}$ concentrations in hair were found to be in the range from 60 to $820 \mathrm{pg} / \mathrm{mg}$ hair. Similarly, Maublanc et al., ${ }^{11}$ identified and quantified 35 psychotropic drugs and metabolites in hair by LC-MS/MS. The limits of detection and quantification ranged from 0.5 to $10 \mathrm{pg} / \mathrm{mg}$. Pufal et al., ${ }^{12}$ reported the presence of the possibility of using an alternative material as hair for determining citalopram, an antidepressant drug and its metabolite, desmethylcitalopram, in hair using liquid chromatography coupled with electrospray-ionization mass spectrophotometry (LC-ESI-MS). Determination was done in individuals who had been administered citalopram in therapeutic doses at least for 12 months before sample collection. Citalopram concentration was found to be 1.04-8.69 ng/ $\mathrm{mg}$ and for desmethylcitalopram, the concentration ranged from 0.07 $1.27 \mathrm{ng} / \mathrm{mg}$ hair. ${ }^{12}$ Capillary electrophoresis (CE) also represents a good analytical tool which has proved suitable for the investigation of illicit drugs in seized preparations including hair. For the investigation of hair for drugs of abuse, capillary electrophoresis proved effective, providing simultaneous determinations of different drugs without derivatization, with acceptable sensitivity. ${ }^{13}$ 


\section{Blood}

Blood has been used as the primary sample for forensic toxicological analysis following death of any person. Several studies used blood for determining a number of compounds for forensic analysis. ${ }^{4,6,14,15}$ A study examined the feasibility of preparing freezedried whole blood samples containing drugs of interest to be used as assay controls. ${ }^{16}$ The application of finger-prick and related dried blood spots (fpDBS) for carbohydrate deficient transferrin (CDT) detection appears suitable for the screening of chronic alcohol abuse. ${ }^{6}$ Parallel serum samples were collected from each investigated subject $(\mathrm{N}=$ 47 ) and the \% CDT for each sample was measured using HPLC and Capillary Zone Electrophoresis (CZE) techniques. fpDBS CZE CDT percentage levels demonstrated a significant statistical correlation with those obtained from serum for both HPLC and CZE \% CDT $\left(\mathrm{p}<0.01 ; \mathrm{r} 2=0.8913\right.$ and 0.8976 , respectively). ${ }^{6}$ Carlier et al. ${ }^{4}$ presented a technique for measuring thirty-nine toxic components of plant origin in the blood, covering a large amount of toxins from local or exotic plants including alpha-lobeline, alpha-solanine, brucine, cephalomannine, colchicine, lupanine, mitragynine, neriifolin, oleandrin, ouabain, paclitaxel, senecionine, sparteine, strophanthidin, strychnine, veratridine and yohimbine using an original ultra-high performance liquid chromatography separation coupled with tandem mass spectrometry detection. The method was found to be sensitive with limit of detection from 0.1 to $1.6 \mu \mathrm{g} / \mathrm{L} .{ }^{4}$ Another study reported a gas chromatographic method to measure blood, serum or plasma concentrations for more than 40 basic drugs with sensitivity of 0.05 $\mathrm{mg} / \mathrm{L}$ or less. ${ }^{14}$ Determination of opiates and their glucuronides in body fluids has a great practical interest in the forensic assessment of heroin intoxication. A selective and sensitive method for quantification of morphine and its 3- and 6-glucuronides, codeine, codeine glucuronide and 6-monoacetylmorphine (6-MAM) based on liquid chromatography-electrospray ionisation mass spectrometry is described by Dienes-Nagy et al. ${ }^{15}$ The limits of quantification were found to be $0.5 \mathrm{ng} / \mathrm{ml}$ for morphine and 6-MAM and $1 \mathrm{ng} / \mathrm{ml}$ for the 6-glucuronide of morphine, codeine-6-glucuronide and codeine and 5 $\mathrm{ng} / \mathrm{ml}$ for the 3 -glucuronide of morphine.
Determination of Beta-hydroxybutyric acid (BHB) may be relevant in the forensic laboratory as ketoacidosis, an elevated level of ketone bodies may contribute to the cause of death. In a study ${ }^{17}$ aimed at determining the relevance of routinely implementing BHB analysis in the forensic toxicological laboratory by analysing BHB in 599 cases, comprising 553 blood, 232 urine and 62 vitreous humour samples. Cases with BHB concentrations above $100 \mathrm{mg} / \mathrm{L}$ in blood and urine were found to be associated with elevated levels of acetone. Similarly, Hoiseth et al., ${ }^{18}$ investigated the kinetics of ethanol and its metabolite ethyl glucuronide (EtG) in blood and urine during the whole time course of absorption and elimination. Blood samples were collected for $14 \mathrm{~h}$ after the start of drinking. It was observed that EtG reached its maximum concentration $(\mathrm{Cmax})$ in blood after a median of $4 \mathrm{~h}$ (range 3.5-5), a median of $3 \mathrm{~h}$ (range 2-4.5) after Cmax for ethanol. ${ }^{18}$ Similarly, Jones ${ }^{19}$ studied the disappearance rate of ethanol from the blood of human subjects and outlines major developments in knowledge about the human metabolism of ethanol. The factors that influenced the rate of ethanol elimination from blood were found to be the amount of ethanol ingested, the drinking habits of the subjects and the effect of food taken together with or before drinking. The slowest rate of ethanol disappearance was observed in a healthy male subject who ingested $0.68 \mathrm{~g}$ ethanol $/ \mathrm{kg}$ body weight after an overnight $(8 \mathrm{~h}$ ) fast with the beta-slope of $9 \mathrm{mg} / \mathrm{dL} / \mathrm{h}$. The fastest rate of ethanol disappearance was observed in a male chronic alcoholic during detoxification with the beta-slope of $36 \mathrm{mg} / \mathrm{dL} / \mathrm{h} .{ }^{19}$ Similarly other methods including reversed phase UPLC-MS/MS ${ }^{20}$ and liquid chromatography-single stage or tandem mass spectrometry (LC-MS or LC-MS/MS) ${ }^{21}$ were used to analyze various drugs in the blood samples of the persons under investigation. Likewise development and validation of an EI-GC-MS method ${ }^{22}$ for the determination of benzodiazepine drugs and their metabolites and simple GC-MS method $^{23}$ for the simultaneous determination of 11 anti-cholinesterase pesticides in blood has also been reported. Table 1 summarizes the analytical methods used along with the type of samples used in different studies in drug analysis.

Table I Studies using different biological samples and various analytical techniques for forensic toxicological assessments

\begin{tabular}{|c|c|c|c|c|}
\hline Sr. No. & Authors & Samples & Method Used & Reference \\
\hline 1 & Bynum et al.,' & Urine and blood & $\begin{array}{l}\text { Laser diode thermal desorption-tandem mass spectrometry } \\
\text { LDTD-MS-MS }\end{array}$ & I \\
\hline 2 & Carlier et al.., ${ }^{4}$ & Blood & $\begin{array}{l}\text { Ultra-high performance liquid chromatography-tandem mass } \\
\text { spectrometry }\end{array}$ & 4 \\
\hline 3 & Dienes-Nagy et al., ${ }^{15}$ & Blood & Liquid chromatography-electrospray mass spectrometry & 15 \\
\hline 4 & Fenton et al.., ${ }^{24}$ & Urine & $\begin{array}{l}\text { Enzyme immunoassay and gas chromatography/mass } \\
\text { spectrometry }\end{array}$ & 24 \\
\hline 5 & Ishii et al., ${ }^{25}$ & Biological samples & $\begin{array}{l}\text { Gas chromatography-surface ionization organic mass } \\
\text { spectrometry }\end{array}$ & 25 \\
\hline 6 & Kauert et al., ${ }^{26}$ & Biological samples & Chemical ionization mass spectrometry with ammonia & 26 \\
\hline 7 & Kharbouche et al., 9 & Hair & $\begin{array}{l}\text { Gas chromatography-negative chemical ionization tandem mass } \\
\text { spectrometry }\end{array}$ & 9 \\
\hline 8 & Marquet $^{27}$ & Blood and urine & Liquid chromatography-mass spectrometry & 27 \\
\hline 9 & Maurer ${ }^{28}$ & blood, plasma, serum, or urine & Liquid chromatography-mass spectrometry & 28 \\
\hline 10 & Ojanpera et al.., ${ }^{29}$ & Biological samples & High-resolution mass spectrometry & 29 \\
\hline 11 & Van Bocxlaer et al., ${ }^{30}$ & Biological samples & Liquid chromatography-mass spectrometry & 30 \\
\hline
\end{tabular}




\section{Urine}

Urine drug testing (UDT) services are provided by a variety of forensic laboratories. Urine is a preferred sample as it is easy to procure for forensic findings. Drugs and drug metabolites can be the target chemicals for the findings of the forensic explorations in different modes of deaths. Some laboratories now provide UDT specifically designed for monitoring patients on chronic opioid therapy. ${ }^{31}$ Some researches point out the relevance of taking urine as a biological sample of interest to find out various drugs under forensic application. ${ }^{18,32,33}$ Hoiseth et al., ${ }^{18}$ investigated the kinetics of ethanol and its metabolite ethyl glucuronide (EtG) in blood and urine; and found that concentrations of EtG were always much higher in urine than in blood. The total amount of EtG excreted in the urine was having a median of $30 \mathrm{mg}$ (range $21.5-39.7$ ), representing $0.017 \%$ (median, range 0.013-0.022) of the ethanol given, on a molar basis. ${ }^{18}$ In a study, the use of liquid chromatography coupled to low-resolution and high-resolution multiple stage mass analyzers was reviewed to metabolic studies, structure elucidation and qualitative or quantitative screening of drugs in different biological samples including urine. ${ }^{32}$ Similarly another study developed a full-scan gas chromatographymass spectrometry procedure for monitoring kratom or Krypton intake in urine. Kratom is a medicinal plant Mitragyna speciosa which is misused as a herbal drug. A new herbal blend (Krypton) has appeared in market which is a mixture of O-demethyltramadol (ODT) and kratom. The limits of detection were $100 \mathrm{ng} / \mathrm{ml}$ for the parent alkaloids and $50 \mathrm{ng} / \mathrm{ml}$ for ODT. ${ }^{33}$

\section{Nails}

Drug analysis in keratinized matrices, such as hair and nails, has received considerable attention. ${ }^{34,35}$ Using keratinized samples has several advantages over methodologies employing body fluids. Long term exposures to different drugs result in the accumulation of the same in these structures. Nails have been shown to accumulate drugs following a long duration of drug intake. Finger and toenails can accumulate drugs during long term exposure. ${ }^{34}$ In a study, determinations were done in fingernail and toenail samples originating from individuals who had been administered flupentixol, an antidepressant, in therapeutic doses for at least 12 months before sample collection using liquid chromatography coupled with electrospray-ionization mass spectrophotometry (LC-ESI-MS). The nail flupentixol concentration was within the range of 0.086-0.109 $\mathrm{ng} / \mathrm{mg}$ and $0.036-0.042 \mathrm{ng} / \mathrm{mg}$ after 4 and 6 months respectively of discontinuation of the drug. With passing months, the levels dropped further and flupentixol was no longer found in nails after ten months of therapy. ${ }^{36} \mathrm{~A}$ similar study presented the possibility of using hair for determination of citalopram and its metabolite desmethylcitalopram.

\section{DNA}

In some incidences or accidents, dead bodies are found in bad conditions so that physical identification is not possible. Depending upon the nature of a particular accident, their body components are often scattered, disintegrated, commingled, contaminated or putrefied. ${ }^{5}$ As the time passes, body starts disintegrating and decomposers start to feed upon them. Body components of aviation accident fatalities are often scattered and disintegrated. ${ }^{37}$ These factors impose difficulties with victim identification, tissue matching and consequently authentic sample analysis and result interpretation. ${ }^{5}$ These issues can be resolved using the technique of DNA typing. Chaturvedi et al., ${ }^{5}$ examined the biological samples from accidental cases for six independently inherited genetic loci using polymerase chain reaction (PCR). Here, three cases were reported and results were postulated on the basis of DNA analysis. Out of these three, one situation was related to the presence of atropine at toxic concentrations in the blood (318 ng/ $\mathrm{mL})$ and lung $(727 \mathrm{ng} / \mathrm{g})$ with its absence in the liver, spleen, and brain. But DNA analysis of the blood and liver samples exhibited their common identity, ensuring that the submitted samples had originated from a single individual. ${ }^{5}$ These types of studies indeed emphasize the important role of PCR and DNA typing in forensic applications. Aviation accident fatalities are also reported to be checked through the mode of DNA profiling. ${ }^{37}$ DNA profiling was performed only in 15 (approximately $0.5 \%$ ) of the 3319 accidents submitted to Civil Aerospace Medical Institute (CAMI). In six accidents out of the total submitted to CAMI, contradictory toxicological findings led CAMI to initiate DNA profiling. The paper by Chaturvedi et al., ${ }^{37}$ demonstrated that the number of aviation accident cases requiring DNA profiling was small but DNA approach was effectively applied in resolving indentifications associated with those accidents.

\section{Conclusion}

Forensic toxicology is the branch of science dealing with the investigation of drugs of abuse. There is a gradual increase in the popularity of this field. Forensic toxicology involves the use of different samples procured from the subjects including hair, blood, urine and nails for the analysis of a variety of drugs using different analytical techniques such as laser diode thermal desorption-tandem mass spectrometry (LDTD-MS-MS), ultra-high performance liquid chromatography - tandem mass spectrometry and liquid chromatography - electrospray mass spectrometry. Forensic toxicology involves the use of high precision instruments and techniques. The field is gaining popularity with passage of time. The author is of the view that this field will grow more with a progressive evolution of different analytical techniques in the near future.

\section{Acknowledgments}

None.

\section{Conflicts of interest}

None.

\section{References}

1. Bynum ND, Moore KN, Grabenauer M. Evaluation of laser diode thermal desorption-tandem mass spectrometry (LDTD-MS-MS) in forensic toxicology. J Anal Toxicol. 2014;38(8):528-535.

2. Bogusz MJ. Hyphenated liquid chromatographic techniques in forensic toxicology. J Chromatogr B Biomed Sci Appl. 1999;733(1-2):65-91.

3. Canale M, Bistarini S, Merler M. Chromatography by silica-gel chromatobars. Prospects of its application in the field of forensic toxicology. Arch Toxicol. 1977;37(2):143-147.

4. Carlier J, Guitton J, Romeuf L, et al. Screening approach by ultra-high performance liquid chromatography-tandem mass spectrometry for the blood quantification of thirty-four toxic principles of plant origin. Application to forensic toxicology. J Chromatogr B Analyt Technol Biomed Life Sci. 2015;975:65-76.

5. Chaturvedi AK, Vu NT, Ritter RM, et al. DNA typing as a strategy for resolving issues relevant to forensic toxicology. J Forensic Sci. 1999;44(1):189-192. 
6. Bertaso A, Sorio D, Vandoros A, et al. Use of finger-prick dried blood spots (fpDBS) and capillary electrophoresis for carbohydrate deficient transferrin (CDT) screening in forensic toxicology. Electrophoresis. 2016;37(21):2867-2874.

7. Barroso M, Gallardo E, Vieira DN, et al. Hair: a complementary source of bioanalytical information in forensic toxicology. Bioanalysis. 2011;3(1):67-79.

8. Klausz G, Kass K, Sotonyi P, et al. Hair analysis of abused and therapeutic drugs in forensic toxicology. Orv Hetil. 2006;147(45):2181-2186.

9. Kharbouche H, Sporkert F, Troxler S, et al. Development and validation of a gas chromatography-negative chemical ionization tandem mass spectrometry method for the determination of ethyl glucuronide in hair and its application to forensic toxicology. J Chromatogr B Analyt Technol Biomed Life Sci. 2009;877(23):2337-2343.

10. Maze T. Hair Analysis in Clinical and Forensic Toxicology. Occup Med (Lond). 2016;66(9):758-759.

11. Maublanc J, Dulaurent S, Morichon J, et al. Identification and quantification of 35 psychotropic drugs and metabolites in hair by LC-MS/MS: application in forensic toxicology. Int J Legal Med. 2015;129(2):259-268.

12. Pufal E, Sykutera M, Nowacka T, et al. Development of a method for estimation of citalopram and desmethylcitalopram in nails and hair and its usefulness in forensic toxicology. Arch Med Sadowej Kryminol. 2010;60(4):216-222.

13. Tagliaro F, Smyth WF, Turrina S, et al. Capillary electrophoresis: a new tool in forensic toxicology. Applications and prospects in hair analysis for illicit drugs. Forensic Sci Int. 1995;70(1-3):93-104.

14. Dawling S, Ward N, Essex EG, et al. Rapid measurement of basic drugs in blood applied to clinical and forensic toxicology. Ann Clin Biochem. 1990;27(5):473-477.

15. Dienes Nagy A, Rivier L, Giroud C, et al. Method for quantification of morphine and its 3- and 6- glucuronides, codeine, codeine glucuronide and 6-monoacetylmorphine in human blood by liquid chromatographyelectrospray mass spectrometry for routine analysis in forensic toxicology. J Chromatogr A. 1999;854(1-2):109-118.

16. Osselton MD, Japp M, Weston SI, et al. Whole blood quality assurance control samples for forensic toxicology. J Anal Toxicol. 1990;14(5):318319 .

17. Sadones N, Lambert WE, Stove CP. The (non)sense of routinely analysing beta-hydroxybutyric acid in forensic toxicology casework. Forensic Sci Int. 2017;274:38-43.

18. Hoiseth G, Bernard JP, Karinen R, et al. A pharmacokinetic study of ethyl glucuronide in blood and urine: applications to forensic toxicology. Forensic Sci Int. 2007;172(2-3):119-124.

19. Jones AW. Disappearance rate of ethanol from the blood of human subjects: implications in forensic toxicology. J Forensic Sci. 1993;38(1):104-118.

20. Karinen R, Vindenes V, Hasvold I, et al. Determination of a selection of anti-epileptic drugs and two active metabolites in whole blood by reversed phase UPLC-MS/MS and some examples of application of the method in forensic toxicology cases. Drug Test Anal. 2015;7(7):634-644.

21. Maurer HH. Multi-analyte procedures for screening for and quantification of drugs in blood, plasma, or serum by liquid chromatography-single stage or tandem mass spectrometry (LC-MS or LC-MS/MS) relevant to clinical and forensic toxicology. Clin Biochem. 2005;38(4):310-318.
22. Papoutsis II, Athanaselis SA, Nikolaou PD, et al. Development and validation of an EI-GC-MS method for the determination of benzodiazepine drugs and their metabolites in blood: applications in clinical and forensic toxicology. J Pharm Biomed Anal. 2010;52(4):609614.

23. Papoutsis I, Mendonis M, Nikolaou P, et al. Development and validation of a simple GC-MS method for the simultaneous determination of 11 anticholinesterase pesticides in blood--clinical and forensic toxicology applications. J Forensic Sci. 2012;57(33):806-812.

24. Fenton J, Schaffer M, Chen NW, et al. A comparison of enzyme immunoassay and gas chromatography/mass spectrometry in forensic toxicology. J Forensic Sci. 1980;25(2):314-319.

25. Ishii A, Watanabe Suzuki K, Seno H, et al. Application of gas chromatography-surface ionization organic mass spectrometry to forensic toxicology. J Chromatogr B Analyt Technol Biomed Life Sci. 2002;776(1):3-14.

26. Kauert G, Drasch G, von ML. Possibilities of using chemical ionization mass spectrometry with ammonia as the selective reaction gas in forensic toxicology. Beitr Gerichtl Med. 1979;37:329-335.

27. Marquet P. Progress of liquid chromatography-mass spectrometry in clinical and forensic toxicology. Ther Drug Monit. 2002;24(2):255-276.

28. Maurer HH. Current role of liquid chromatography-mass spectrometry in clinical and forensic toxicology. Anal Bioanal Chem. 2007;388(7):13151325 .

29. Ojanpera I, Kolmonen M, Pelander A. Current use of high-resolution mass spectrometry in drug screening relevant to clinical and forensic toxicology and doping control. Anal Bioanal Chem. 2012;403(5):12031220 .

30. Van Bocxlaer JF, Clauwaert KM, Lambert WE, et al. Liquid chromatography-mass spectrometry in forensic toxicology. Mass Spectrom Rev. 2000;19(4):165-214.

31. Reisfield GM, Goldberger BA, Bertholf RL. Choosing the right laboratory: a review of clinical and forensic toxicology services for urine drug testing in pain management. J Opioid Manag. 2015;11(1):37-44.

32. Meyer GM, Maurer HH, Meyer MR. Multiple stage MS in analysis of plasma, serum, urine and in vitro samples relevant to clinical and forensic toxicology. Bioanalysis. 2016;8(5):457-481.

33. Philipp AA, Meyer MR, Wissenbach DK, et al. Monitoring of kratom or Krypton intake in urine using GC-MS in clinical and forensic toxicology. Anal Bioanal Chem. 2011;400(1):127-135.

34. Palmeri A, Pichini S, Pacifici R, et al. Drugs in nails: physiology, pharmacokinetics and forensic toxicology. Clin Pharmacokinet. 20071;38(2):95-110.

35. Baumgartner MR. Nails: an adequate alternative matrix in forensic toxicology for drug analysis? Bioanalysis. 2014;6(17):2189-2191.

36. Pufal E, Sykutera M, Piotrowski P. Development of a method for determining antidepressant drugs in nails and its usefulness in forensic toxicology. Arch Med Sadowej Kryminol. 2008;58(4):167-170.

37. Chaturvedi AK, Craft KJ, Kupfer DM, et al. Resolution of aviation forensic toxicology findings with the aid of DNA profiling. Forensic $\mathrm{Sci}$ Int. 2011;206(1-3):81-86. 